\title{
Rupture of a ventricular abscess after mitral valve replacement
}

\author{
A E Weale, J Hutter, C M P Collins
}

\begin{abstract}
A 65 year old man presented with bacterial endocarditis of the mitral valve. Immediately after mitral valve replacement a valve ring abscess ruptured.

Early surgery should be performed when an intramyocardial abscess is suspected.
\end{abstract}

There are 1500 cases of infective endocarditis in the United Kingdom each year with an overall mortality of $34 \% .{ }^{1}$ Despite the greater awareness of bacterial endocarditis and emphasis placed on prophylaxis and early treatment over the past 25 years, surgical treatment is occasionally required. The aortic valve is affected in $42 \%$ and the mitral valve in $48 \%$ of cases. Bacterial endocarditis of the tricuspid valve is associated with drug addiction. We describe a very rare complication of the disease and discuss the management of myocardial abscess.

\section{Case report}

A 65 year old man was admitted acutely confused with a two month history of general debility and weight loss. $\mathrm{He}$ was pale, dehydrated, and feverish. A single subungual splinter haemorrhage was seen. The spleen was palpable. A pansystolic murmur consistent with mitral regurgitation was heard.

Initial laboratory results were haemaglobin $7 \cdot 1 \mathrm{~g} / \mathrm{dl}$, total white blood cell count $4 \cdot 1 \times 10^{3} / 1$, blood urea $25 \cdot 1 \mathrm{mmol} / 1$, and serum creatinine $402 \mu \mathrm{mol} / 1$. The electrocardiogram showed left bundle branch block. The chest radiograph showed moderate cardiac enlargement and blunting of the costophrenic angle. Ultrasound examination of his abdomen showed normal kidneys and a grossly enlarged spleen. Echocardiography showed severe mitral regurgitation and a vegetation on the anterior mitral leaflet. There was no evidence of abscess formation. Blood cultures grew Streptococcus mutans sensitive to benzylpenicillin and netilmicin.

The patient was treated with intravenous netilmicin, benzylpenicillin, diuretics, and a blood transfusion. There was initial clinical improvement with resolution of both fever and confusion. Subsequently renal function deteriorated, confusion recurred, and congestive cardiac failure refractory to medical treatment developed. Coronary angiography showed a $70 \%$ diameter stenosis of the left anterior descending artery.
Urgent mitral valve replacement was performed eight weeks after admission. At operation the heart was moderately enlarged, with pulmonary hypertension and a large pulsating left atrium. Cardiopulmonary bypass was instituted and myocardial protection achieved with cold crystalloid cardioplegia and moderate hypothermia $\left(28^{\circ} \mathrm{C}\right)$. The anterior cusp of the mitral valve was totally flailed because its chordae tendineae were ruptured. Several chordae of the posterior cusp were also ruptured. There were multiple vegetations on the valve. There was an abscess cavity in the posterior part of the annulus extending into the ventricular myocardium. The valve was excised and a $29 \mathrm{~mm}$ CarboMedic bileaflet prosthetic valve was inserted with $2 / 0$ Ethibond sutures buttressed on Teflon felt pledgets. Posteriorly the sutures were placed to close the mouth of the abscess cavity. In this region, however, the tissues were very thin and friable. The patient was weaned from bypass satisfactorily and required minimal inotropic support $(3 \mu \mathrm{g} / \mathrm{kg} /$ min dopamine). Haemostasis was satisfactory and the operation was completed.

Reoperation was required urgently two hours postoperatively because off sudden excessive blood loss. We found that the abscess cavity in the posterior atrioventricular groove had ruptured. Cardiopulmonary bypass was reinstated but attempts to control the haemorrhage failed.

At necropsy the prosthetic mitral valve was found to be well seated and its suture line secure. The left ventricle showed considerable hypertrophy without dilatation. In the postero-lateral wall, lying just below the mitral valve ring, an endocardial performation $0.8 \mathrm{~cm}$ in diameter communicated with an epicardial haemorrhage (figure). The intramyocardial defect had the appearance of an abscess cavity. Externally there was an epicardial performation $1.0 \mathrm{~cm}$ in diameter.

Histological examination showed that the wall of the intramyocardial cavity was composed of a layer of necrotic myocardial tissue covered by thrombus.

\section{Discussion}

Left ventricular rupture as a complication of mitral valve replacement was first reported by Roberts and Morrow. ${ }^{2}$ In a published series it reported in between $0.5 \%$ and $2 \%$ of all mitral valve replacements and was fatal in $75 \%$ of these cases. A survery of reports in English found 125 cases. $^{3}$ Only one of these showed rupture through the base of a myocar- 
Oblique cut through the lateral part of the mitral valve ring showing the endocardial perforation (arrow) and extensive epicardial haemorrhage.

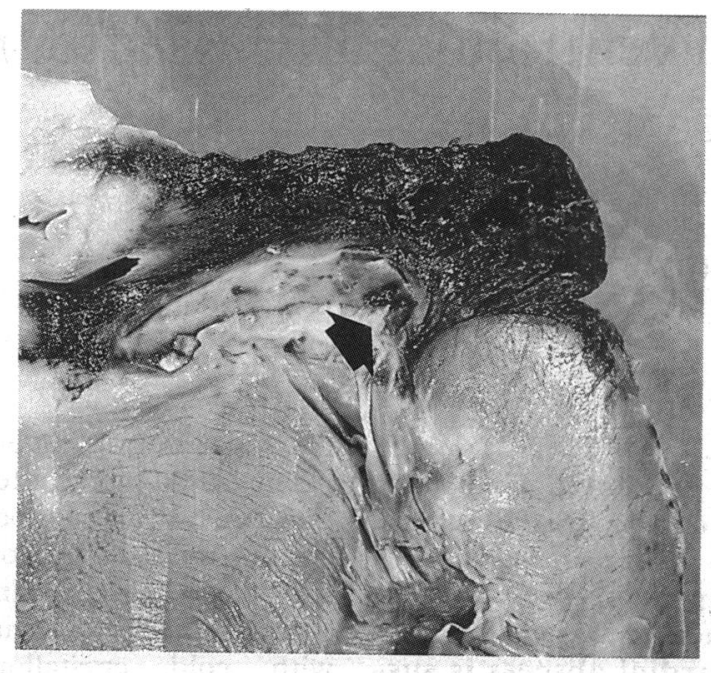

dial abscess caused by infective endocarditis. Left ventricular rupture is usually attributed to technical steps in the operation or to stretch injury produced by untethering of the left ventricle through removal of the mural leaflet of the mitral valve. Those patients most at risk are generally frail elderly women who have a small ventricular cavity and thin myocardium associated with long-standing mitral stenosis.

There is only one other report of rupture through a ventricular myocardial abscess after mitral valve replacement. ${ }^{2}$ Necropsy studies show that valve ring abscesses are a more frequent complication of infective endocarditis affecting the aortic valve. ${ }^{4}$ In these cases the myocardial abscess is often associated with infection by Staphylococcus aureus, pericarditis, various degrees of atrioventricular block, short duration of symptoms, or new onset of aortic insufficiency. Non-paroxysmal junctional tachycardia and Wenckebach or complete heart block with a QRS of normal width are all consistent with inflammation adjacent to the mitral valve. ${ }^{5}$ Abscesses associated with both aortic and mitral valves occur more frequently when the infecting organism is a highly virulent one, such as a pneumococcus or staphylococcus, and occasionally an $\alpha$ streptococci.

Preoperative diagnosis can be difficult. Methods that have been used to detect myocardial abscess formation include echocardiography, computed tomography of the chest, gallium scanning, and ${ }^{111}$ In platelet scintigraphy. The sensitivity of echocardiography and computed tomography is low. ${ }^{6}$ Gallium imaging for endocarditis or abscess formation is not widely used, and scintigraphy with ${ }^{111}$ In labelled leucocytes has not yet been fully evaluated.

Studies attest to the poor prognosis of patients with myocardial abscess. ${ }^{47}$ The development of a valve ring abscess is always an indication for prompt surgical intervention with excision of infected material and valve replacement. Without this, and despite appropriate antibiotic therapy, mortality remains high. Annular inflammation and the friability of tissues creates difficulty in seating the prosthetic valve. There is a risk of postoperative valve insufficiency. Early diagnosis of the developing abscess offers the only hope for achieving surgical success.

This case illustrates a rare complication of mitral valve replacement in a patient with infective endocarditis. The grave prognosis of myocardial abscess justifies surgical intervention.

We thank Mr G Keen for permission to publish this report.

1 Schurr LP, Ball AP, Geddis AM, Gray J, McGhie D. Bacterial endocarditis in English in the 1970's. A review of 70 patients. QJ Med 1977;46:499-512

2 Roberts WC, Morrow AG. Cause of early postoperative death following cardiac valve replacement. $J$ Thorac Cardiovasc Surg 1967;54:422-43.

3 Karlson KJ, Ahraf MM, Berger RL. Rupture of left ventricle following mitral valve replacement. Ann Thorac Surg 1988;46:590-7.

4 Arnet EN, Roberts WC. Valve ring abscess in active infective endocarditis. Circulation 1976;54:141-5.

5 Hosea SW. Virulent streptocon 1976;54:141-5. endocarditis. Am Heart $J$ 1981;101/2:174-6.

6 Cerqueria MD, Jacobson AF. Indium ${ }^{111}$ leucocyte scintigraphic detection of myocardial abscess formation in patients with endocarditis. J Nucl Med 1989;30:703-6.

7 Weaver JP, Crawford FA, Kratz JM, Sade RM. Valve replacement for native valve endocarditis. Am Surg 1984;50:40-2. 